DOI 10.37882/2500-3682.2020.11.07

\title{
ЗАБЛУЖДЕНИЯ О ВЗГЛЯДАХ КОНФУЦИЯ НА РОЛЬ ЖЕНЩИНЫ И ИХ ВЛИЯНИЕ НА СОВРЕМЕННОЕ ЖЕНСКОЕ ОСВОБОДИТЕЛЬНОЕ ДВИЖЕНИЕ
}

\section{MISCONCEPTIONS ABOUT CONFUCIUS' VIEWS ON THE ROLE OF WOMEN AND THEIR IMPACT ON THE MODERN WOMEN'S LIBERATION MOVEMENT}

Geng Biao

A. Alekseev-Apraksin

Summary: The article examines in detail the relationship between the thoughts of Confucius and the social status of women. By analyzing the views of «yin» and «yang» in Confucianism and rethinking various ideas in the Confucian classics, Confucius's view of the equal status of men and women is revised. At the same time, it also talks about the influence of historical and political factors on various ideas developed by Confucianism in the process of communication, which once again confirmed Confucius's statement about the status of women. Confucianism claims that a woman is absolutely and unconditionally inferior to a man. Her first and foremost duty is to obey her husband and parents, maintain order in the house and give birth to healthy boys. The emphasis was on her biological function, and her emotional life was relegated to the background. The author says that misinterpretations of Confucius's teachings about the role of women have become a serious obstacle to the study of Confucianism by some foreign scholars, since it is very difficult for foreign scholars to truly understand Confucian thoughts through the existing translation, and this has seriously affected the spread of Confucianism in the world. The result of the analysis can provide theoretical support for the modern women's liberation movement. Based on the long-term trust of the Chinese people in Confucianism, this material may also have some reference value for the future development of China's social structure.

Keywords: Confucius, China, status of a woman, Yin 阴 and Yang 阳, inferior person, female virtue.
$\mathrm{H}$ а протяжении более двух тысяч лет, мысли Конфуция оказывали глубокое влияние на политические, экономические, социальные, культурные и другие аспекты жизни Китая. Многие из них искажались из-за потребностей правителей или изменений в интерпретации более поздних исследователей конфуцианства. Это особенно коснулось темы «социального статуса женщины». Эти неверные интерпретации не только исказили первоначальные высказывания и их подтекст Конфуция, но и оказали плохое влияние на развитие политики и общества Китая, особенно в освободительном движении женщин.
Гэн Бяо

Аспирант, Санкт-Петербургский государственный университет

gengbiao1994@mail.ru

Алексеев-Апраксин Анатолий Михайлович

Д.культурологии, профессор, Санкт-Петербургский государственный университет

Аннотация: В статье подробно рассматривается взаимосвязь мыслей Конфуция и социального статуса женщин. Посредством анализа взглядов «инь» и «ян» в конфуцианстве и переосмысления различных идей в конфуцианской классике, взгляд Конфуция на равный статус мужчин и женщин пересматривается. В то же время также говорится о влиянии исторических и политических факторов на различные идеи, выработанные конфуцианством в процессе общения, из-за этого Конфуций и конфуцианство были неправильно поняты. Считается, что конфуцианство утверждает, что женщина абсолютно и безусловно стоит ниже мужчины. Ее первый и основной долг состоит в том, чтобы повиноваться мужу и родителям, поддерживать порядок в доме и рожать детей. Акцент делался на биологической функции женщины, а эмоциональная жизнь отодвигалась на второй план. Автор говорит 0 том, что неверные интерпретации учения Конфуция по поводу роли женщины стало серьезным препятствием для изучения конфуцианства некоторыми иностранными учеными, так как иностранным ученым очень трудно понастоящему понять конфуцианские мысли через существующий перевод, и это серьезно отразилось на распространение конфуцианства в мире. Результат анализа может оказать теоретическую поддержку современному женскому освободительному движению. Основываясь на долгосрочном доверии китайского народа к конфуцианству, данный материал также может иметь определенную справочную ценность для будущего развития социальной структуры Китая.

Ключевые слова: Конфуция, Китая, статус женщины, Инь 阴и Ян 阳, низший человек, женская добродетель.

Основная идея в конфуцианстве - «гуманное правление仁政», то есть правитель должен обращать внимание на людей. В идеях Конфуция мужчины, женщины, пожилые люди и дети одинаково важны и нуждаются в заботе правителя. Последующие правители придерживались взглядов, уничижающих статус женщины, чтобы закрепить и сохранить патриархальное правление, и отклоняясь от конфуцианских постулатов, они истолковывали представления Конфуция о положении и роли женщины и интерпретировали их для удовлетворения своих собственных потребностей. По этой причине Конфуций стал врагом современного женского освободительного движения, и людям трудно по-настоящему понять отноше- 
ние конфуцианства к этому вопросу.

Кроме того, из-за этих ошибочных интерпретаций конфуцианства в Китае долгое время сохранялся неправильный этический кодекс. В современном Китайском народе все еще есть люди, которые берут идею «лелеять мальчиков (сыновей) и пренебрегать девочками (дочерями)重男轻》 и «бесталанная женщина добродетельна, добродетель женщины в отсутствии талантов女子无才 便是德》, и т.д.

Подобные интерпретации учения Конфуция со стороны самих китайцев стало серьезным препятствием для изучения конфуцианства некоторыми иностранными учеными, они часто не могли по-настоящему понять конфуцианские мысли через существующий перевод, что также сильно повлияло на распространение конфуцианства в мире.

Согласно с теорией Инь阴и Ян阳, В «И-цзине» написано, что мир создан союзом Ян и Инь (一阴一阳即为道). В «Записках о благопристойности» также сказано: «Мы из одного места, и это место делится на небо и землю, то есть Инь и Ян, а затем оно делится на четыре сезона是故 夫礼, 必本于大一, 分而为天地, 转而为阴阳, 变而为 四时» [2]. Следует отметить, что конфуцианство считает, что общество состоит из двух противоположных частей - неба и земли, мужчины и женщины, дня и ночи. В отличие от западного дуалистического восприятия мужчин и женщин, Инь и Ян как неконфронтационная, дополняющая диада не дает достаточных оснований для оправдания гендерного угнетения в традиционном Китае. В ней нет концепции доминирования [9].

Различие между Инь и Ян представляет пространство для всестороннего развития обоих полов. Это следует интерпретировать как разницу во времени, в которой доминируют Инь и Ян, и они оба следуют циклическому образцу, повторяя путь восхождения и упадка. Кроме того, динамичная эволюция различия между Инь и Ян также выявляет плюрализм в гендерных отношениях. Сила Инь и Ян претерпевает изменения, и их взаимная сила часто меняется друг с другом. В зависимости от конкретной комбинации сил Инь и Ян на разных уровнях взаимодействие между Инь и Ян возникает во многих отношениях [11].

Например: старший мужчина сильнее, чем женщина, и он Ян. Но по сравнению с молодым человеком он (старик) стал Инь. Но это не означает, что все мужчины не сильны в абсолютном смысле, а также не означает, что все мужчины достигли физического уровня, которого не могут достичь все женщины. Таким образом, с точки зрения Инь и Ян отношения между мужчинами и женщинами являются взаимодополняющими, а не иерархическими.
Считается, что в китайской и восточноазиатской культуре женщинам отводится низкое место. И снова вину за это сваливают на учение о конфуцианстве.

Женщинам действительно уделяется мало времени в конфуцианском учении, но нет никаких оснований считать, что философ относился к ним отрицательно. В конфуцианском «Тысячесловии» есть фраза: «Дома уважай мудрость своей матери».

В качестве отрицательного отношения Конфуция к женщинам часто приводят цитату из «Лунь Юй»: «Труднее всего ладить с женщинами и низкими людьми. Если ведёшь себя с ними дружественно, они теряют скромность. Если сохраняешь дистанцию, они проявляют недовольство女子与小人为难养也, 近之则不逊, 远之则 怨》.

Большинство людей думают, что «низкий человек小 人» в этом предложении означает плохого человека или аморального человека, что Конфуций классифицирует «женщин女子» и «низких людей小人» как один тип людей, не отражает ли это дискриминацию Конфуция в отношении женщин?

Однако это не так. Хотя «小人» и «女子» относится не только к женщинам и низким людям, но и к тем, кто не образован (неграмотен). В древней Китае очень мало людей могут получить образование, не обязательно, чтобы мужчины могли получать образование, а женщины - нет. В тоже время в конфуцианстве антоним «низкий человек小人» - это «благородный муж君子», «низкий человек», на который ссылается Конфуций, также относится к людям без образования, а «благородный муж» - это высокий уровень мышления (способный в порядке содержать семью, управлять государством и нести Поднебесной мир齐家、治国、平天下). Это достигается хорошим образованием. Конечно, нельзя отрицать, что поскольку в группе «неграмотных» женщины составляли большинство, Конфуций относил к «女人» и «小»как «неграмотным» [7].

В то же время Конфуций был пионером общей идеи образования «в получении образования нет различий между людьми有教无类». Задавая вопрос «от кого же зависит совершение гуманных поступков: от себя или же от других?!为仁由已而由人乎哉?!». Он отвечал, что от себя, утверждая, что «гуманный человек любит людей 仁者爱人». Эти идеи не имели никакого посыла об исключении женщин; Мэн-цзы в книге «Мэн-цзы» сказал «никакие женские жалобы внутри семьи, не окажутся не замеченными в жизни внешней内无怨女, 外无旷夫» [4]. Они способны повлиять на содержание социальных идеалов. В текстах до цинского конфуцианства, особенно в «И-Цзине», в мыслях о взаимодополняемости инь 阴 и ян阳, гармонии между небом и землей и в «Записках 
о благопристойности» о «различия существующих между мужчиной и женщиной男女有别》 сказано «мужчина заботится о внешних делах, женщина заботится о внутренних делах 男主内, 女主外》 и уважение кженщинам содержат основополагающее подтверждение женской ценности [16].

Считается по конфуцианству правило для общества соответствует фразе «возвеличивание мужчин и унижение женщин男尊女卑». Прежде всего, нужно прояснить, что эти слова являются лишь частью предложения в «И-Цзине». Полное предложение - «天尊地卑, 乾坤定 矣, 卑高以陈, 贵贱位矣. ..... 乾道成男, 坤道成女》, Coдержит другой смысл [2]. В нем утверждается, что небо вверху, а земля внизу. Что все естественно сформировано. Здесь нет социальной коннотации в определении положения на высоком или низком уровне... Небо символ мужского начала, земля символ женского [9].

В «И-Цзине» написано, что мужчины и женщины являются людьми, и им присущ равный статус, но «различия существуют между мужчиной и женщиной男女有别》, и у каждого есть своя область знаний [2]. Оглядываясь на историю, когда люди вступили в сельскохозяйственное общество, обрабатывание земли и сражения стали важными задачами для выживания и развития. Мужчины имеют существенную физическую силу и более высокий рост, им не нужно рожать и вынашивать детей, и они имеют преимущества во времени и свободе. На историческом этапе, когда от производительности, зависело накопление и сохранения богатств, чем четче разделение труда, тем больше разница между мужчинами и женщинами. В военном, политическом и пахотном производстве преобладали мужчины, а в ведении домашнего хозяйства, ткачества, преобладали женщины. Поэтому в положение «возвеличивание мужчины и унижение женщин男尊女卑》, 《尊》 и 《卑»не следует толковать как «возвеличивания» и «унижения», а лишь различать разделение труда между мужчинами и женщинами в обществе им должны соответствовать личностные характеристики. Женщины должны быть такими же инклюзивными и бескорыстными, как земля: а мужчины должны быть такими же активными и самосовершенствующимися, как небо [15].

Конфуций выдвинул теорию «исправления имени正 名», которая также подтверждает эту точку зрения. Он считает, что у каждого своя роль в обществе, и каждый должен делать то, что должен, и не надо делать то, что не соответствует его роли. Если все будут следовать тому, общество сможет развиваться упорядоченным образом. В то же время он считает, что в идеальной семье должна быть «жена, которая нежна и добра, как Гуцинь妻子好， 如鼓琴瑟》, а муж должен быть «совестливый и неизменный, направляющий свою энергию на то, чтобы сделать свою семью гармоничной и стабильной, жену счастли- вой 宜尔室家, 乐尔妻帑》 (из 《ии цзин») [5].

Кроме того, в «Записках о благопристойности» также записано, что, когда мужчина и женщина вступают в брак, жених должен пойти в дом родителей женщины, чтобы забрать её и отвезти домой. После церемонии бракосочетания муж и жена становятся равно статусными «неважно, каков был их социальный статус, главное, чтобы они любили друг друга. 同尊卑, 共相» [1]. Конфуций также сказал, «и император, и простые люди все должны уважать своих жен, это моральный стандарт. 昔 三代明王必敬妻子也, 盖有道也。».

Некоторые ученые считают, что существовал запрет женщин для работы в правительстве в древнем Китае. Это отражает неравный статус мужчин и женщин. На самом деле Конфуций не думал, что женщины не способны выполнять правительственную работу. В «Лунь Юй» записано, что Конфуций разговорил с Чжоу Уван о десяти важных чиновниках: «才难, 不其然乎? 唐虞之际, 于斯 为盛。有妇人焉, 九人而已。»[3]. Значение: талант редок! На протяжении всей истории. Сейчас время, когда в стране больше всего талантов. Среди десяти чиновников, которые управляют страной, должна быть женщина, отвечающая за внутренние дела. Девять административных чиновников - не достаточно для благородной страны. Можно видеть, что в идеях Конфуция женщины имеют такой же статус, что и мужчины, и они также могут управлять страной, как мужчины в рамках учения Конфуция о разделении труда [8;14].

Со времен античности (за исключением варварских народов) на Западе женщины не имели права голоса в обществе. Это связано с тем, что их считали иррациональными, а их интересы часто представляли мужчины (муж или отец). Конфуцианство никогда не разделяло чувствительность и рациональность, поэтому этот принцип исключительности не применим к конфуцианству. Поэтому в конфуцианстве женская чувствительность и мужское рациональное выражение не признаются [13].

В то же время, согласно исследованиям, Хао Давэй и Ань Леже, было обнаружено, что идеальная личность в конфуцианстве включает в себя слияние мужских и женских качеств. Следовательно, в конфуцианстве женщины не могут быть исключены из политики. У них есть способность выносить объективные суждения. Они не столь глупы, как думали западные люди [10].

И китайская традиционная «женская добродетель女 德》 теория «троякая покорность и четыре достоинства 三从四德》 и «три устоя и пять незыблемых правил三纲 五常》 духовных оков и теории «помереть с голоду - не беда, а потерять невинность - большое дело饿死事小, 失节事大» не имеет ничего общего с Конфуцием, эти теории сформировались с династией Сун и Мин. В тот 
конкретный исторический период из-за высокого политического правления, эти теории были выдвинута во имя конфуцианства, чтобы ослабить все более серьезные социальные противоречия [12]. В «Записках о благопристойности» записано, что жена сына Конфуция и жена внука вступают в повторный брак. После смерти сына Конфуция в 50 лет его жена вышла замуж за кого-то другого [1]. Можно видеть, что теория о том, что «помереть с голоду - не беда, а потерять невинность - большое дело 饿死事小, 失节事大», не имеет ничего общего с Конфуцием.

Вопреки народным традициям, Конфуций не избегал темы любви между мужчинами и женщинами. В «Ши цзин» он перечислил «Гуань-цзюй关睢》 В «Чжэн Фэн» как первую из трехсот стихов, «洋洋乎盈耳哉》 похвалив искреннюю и восторженную любовь, которую молодые люди проявили в процессе влюбленности друг в друга. Большая часть «Чжэн Фэн» отражает тему любови, а в «Гофэн» выбран двадцать один стих про любовь. И Конфуций считает, что дворяне и обычные люди имеют право на равную любовь, что соответствует основным понятиям конфуцианства: «любовь - это разум性即理也» и «гуманность — это человечность 仁者人也» [5].

Несомненно, что из-за влияния социальной среды жизни понимание Конфуция статуса женщин и равенства между мужчинами и женщинами недостаточно глубокое. Из-за ограничений познания и исторических условий теория Конфуция не будет верна в каждом предложении и может не в полной мере соответствовать потребностям современного общества. Однако в наследовании и развитии конфуцианства должны активно сохранять положительные замечания. Как сказал историк современной классики г-н Чжоу Ютун (1898-1981): «Настоящий Конфуций умер, и фальшивый Конфуций появился в соответствии с изменениями в экономической организации, политической ситуации и академическом мышлении Китая. Император Хан Вуди использовал предложение Дун
Чжуншу, чтобы сохранить и развивать только конфуцианское учение. Фактически, Конфуций, уважаемый династией Хань, был всего лишь фальшивым Конфуцием для политического удобства, по крайней мере, полуправдой и наполовину ложным Конфуцием. Это ни в коем случае не настоящий Конфуций. Если речь идет об академической мысли изменение «Конфуция» тем более. Хотя Конфуций - фигура, которую все знают, Конфуций, которого знают все, не может быть настоящим Конфуцием» [6].

\section{Выво $\triangle$}

В современном мире женское освободительное движение стало горячей темой, поскольку женщины, являющиеся одной из важнейших частей общества, должны иметь такой же социальный статус, что и мужчины. В современном Китае теория, которая препятствует женщинам в достижении равного статуса, является «неверно истолкованным конфуцианством», которое оказывает глубокое влияние на китайскую нацию. Согласно теории инь и янь, нетрудно увидеть, что в концепции Конфуция мужчины и женщины имеют равный статус, а иерархических отношений не существует. Поэтому своевременное исправление неверных толкований конфуцианства также является важной задачей развития современного Китая. В Китае людям присуще чувство доверия к конфуцианству. Древние правители использовали «неверное конфуцианство» для ограничения прав женщин, так и в настоящее время можно использовать конфуцианство для оказания сильной поддержки статусу женщины. Это будет наиболее важной теоретической основой освободительного движения китайских женщин, а также может стать идеальным способом распространения истинной китайской культуры. Конечно, это не означает полный феминизм, но более разумные разделение труда и модель социального развития должны быть реализованы на основе рационального использования преимуществ мужчин и женщин.

\section{ЛИТЕРАТУРА}

1. Записки о благопристойности // Е Хенг комментировал, коммерческое издательство, Тайвань, 12.1964. -250 с.

2. И-цзин // Гао Хэн комментировал, издательство университета Цинхуа, 01.02.2005. -735 c.

3. Лунь Юй // Ченг Шудэ комментировал, Китайское книгоиздательство, 1942. -614 с.

4. Мэн-Цзы // Ян Божун комментировал, Китайское книгоиздательство, 2008. -272 с.

5. Ши цзын // Юй Гуаньин комментировал, Жэньминь вэньсюэ чубаньшэ, 1956. -310 с.

6. Чжоу Ютун «Конфуций, Конг Шэн и Чжу Си» // Шанхайское Жэньминь чубаньшэ, 2012. -228 c.

7. Чэнь Вэньсинь Переосмысление «唯女子与小人为难养也», 02.10.2015, c. 4-11

8. Alison Black, Gender and Cosmology in Chinese Correlative Thinking // Gender and Religion, Caroline Bynum, Stevan Harrell, Paula Richman (Boston: Beacon Press), 1986. p. 594-598

9. Confucianism for the Modern World / Cheng Qianyi // Bell and Chaibong eds. New York: Cambridge University Press, 2003, p. 312-333.

10. David Hall(郝大为), Roger Ames（安乐哲）, Thinking from the Han / Albany: State of New York University Press, 1998, p. 90.

11. Henry Rosemont, Jr., Confucian and Feminist Perspectives on the Self / Culture and Self, ed., Douglas Allen (Colorado: Westview Press), 1997. p. 71 
12. Kelleher Theresa. Confucianism // Women in World Religions. Ed. by Arvind Sharma. Albany: State University of New York Press, 1987. p. 135-159.

13. Lee Lily Xiao Hong. The Virtue of Yin: Studies on Chinese Women. Broadway, Australia: Wild Peony, 1994. p. 118

14. Pao Chia-lin, Readings in Chinese Women History / Taiwan: Cowboy Publishing Ltd, 1979. p. 41

15. Richard Guisso, Stanley Johannesen. Women in China / Youngston: Philo Press, 1981. -238 p.

16. Sin Yee Chan, Gender and Relationship Roles in the Analects and the Mencius // An International Journal of the Philosophical Traditions of the East, 2000. p. 115-132

\footnotetext{
(с) Гэн Бяо (gengbiao1994@mail.ru), Алексеев-Апраксин Анатолий Михайлович

Журнал «Современная наука: актуальные проблемы теории и практики»
}

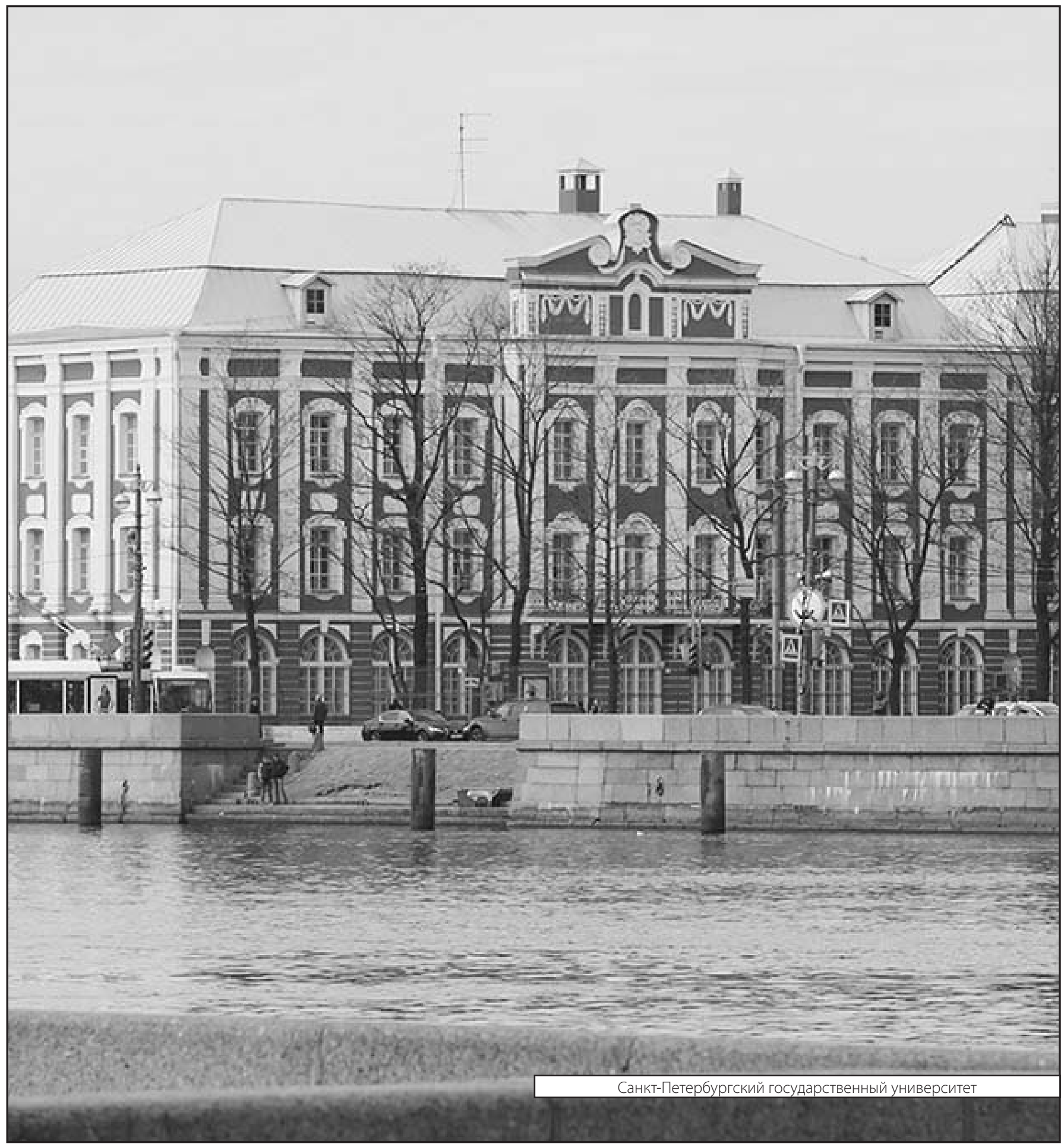

